\title{
Development and Evaluation of an In Vitro Test System for Toxicity Screening of Aerosols Released from Consumer Products and First Application to Aerosols from a Hair Straightening Process
}

\author{
Detlef Ritter, Annette Bitsch,, Manfred Elend, Sven Schuchardt, Tanja Hansen,, \\ Carsten Brodbeck, Jan Knebel, Anne Fuchs, ${ }^{3}$ Claas Gronewold, ${ }^{3, *}$ and Rolf Fautz ${ }^{3}$
}

\begin{abstract}
A cell-based in vitro test system was set up and evaluated for investigations of effects from inhalable aerosols that might be released during use of consumer products. It included a box for generation of aerosols, which was optimized by computational fluid dynamics simulations, aerosol analysis, and a cell exposure device (P.R.I.T. ${ }^{\circledR}$ ExpoCube ${ }^{\circledR}$ ) for air/liquid interface exposure of A549 human lung epithelial cells. The in vitro inhalation model was characterized using lactose or sodium dodecyl sulfate (SDS) or copper-II-sulfate $\left(\mathrm{CuSO}_{4}\right)$ aerosols as negative or positive controls. In a first application, aerosols were generated during use of a commercial hair straightener product, considering a relevant protocol with respect to its use by professional hairdressers. Cellular toxicity and interleukin-8 (IL-8) secretion were analyzed as biological effects of exposure in a worst-case exposure scenario for acute local lung toxicity. Generation of aerosols from controls and the product in comparable particle sizes and efficient aerosol deposition on the cellular surface during exposure enabled dose/response relationships in large dosage ranges. Dose-dependent toxicity was found for the positive controls but not for lactose and different IL-8 responses from SDS, $\mathrm{CuSO}_{4}$, and lactose. Aerosols from the hair straightening product induced nonsignificant effects on IL-8 secretion in one exposure situation only, which were comparable with lactose effects in the same range of dosage. In summary, the cell-based in vitro testing system was successfully established. It might define a relevant basis to get insight into the toxicology of inhalable aerosols with workplace and daily-life relevance using an alternative testing method under highly controlled experimental conditions.
\end{abstract}

Keywords: air/liquid interface, hair straightener, in vitro, inhalation, toxicity

\section{Introduction}

$\mathbf{G}$ ASES, VAPORS, AND AEROSOLS might be released during use of consumer products. The multiple constituents of resulting mixtures are expected to exhibit individual toxicological properties. Moreover, especially in case of aerosols, the exact analysis of the complex airborne gas and droplet or particle matrix is nearly impossible due to kinetical changes, number of compounds, or physicochemical behavior of vapors and particles. Nevertheless, such atmospheres might have a toxicological relevance due to environmental presence in daily life or at workplaces. Hence, toxicological characterization is needed. However, there are several obstacles in the respective safety assessments. First of all, many compounds of the complex atmosphere might not be known. Then, inhalation toxicology data are lacking, especially for chemical "intermediates" during generation. Moreover, the combinatory effects of substances in complex matrices cannot be derived from

\footnotetext{
${ }^{1}$ Fraunhofer Institute for Toxicology and Experimental Medicine (ITEM), Hannover, Germany.

${ }^{2}$ Fraunhofer Institute for Algorithms and Scientific Computing SCAI, Sankt Augustin, Germany.

${ }^{3}$ Safety and Toxicology, KAO Germany GmbH, Darmstadt, Germany.

*Current affiliation: Regulatory Affairs-Pharma Polymers, Evonik Nutrition \& Care GmbH, Darmstadt, Germany.
}

(c) Detlef Ritter et al., 2018; Published by Mary Ann Liebert, Inc. This is an Open Access article distributed under the terms of the Creative Commons Attribution License, which permits unrestricted use, distribution, and reproduction in any medium, provided the original work is properly cited. 
data of the single compounds. ${ }^{1}$ Finally, behavior and characteristics of particles cannot be predicted in such a complex system. In addition, through evaporation, condensation, or surface adsorption effects, particles might also play important roles in transporting compounds into the deeper lung, those compounds would never have reached individually due to their physicochemical properties (e.g., water solubility). Thus, the presence of particles might also change the toxicological behavior of a complex mixture, especially if they are composed of volatile or low-volatile compounds.

Classical approaches to study such situations may include animal inhalation studies. However, aside from the fact that animal experimentation focused on individual products might lead to an unacceptable amount of studies, it is prohibited by EU regulation for some industries such as the cosmetic industry. ${ }^{2}$ Moreover, availability, amount, and characterization of the test aerosols needed for such inhalation studies would also be limiting. Cell-based in vitro methods using ex vivo or in vitro models of the human lung have been applied during the last years to gain insight into toxicological relevant biological effects during inhalation. Regarding complex airborne mixtures, smokes or exhausts have been studied such as diesel exhausts ${ }^{3,4}$ or cigarette smoke. ${ }^{5-7}$ Also, mixtures from volatile organic compounds have been evaluated ${ }^{8-10}$ as well as nanoparticles ${ }^{11,12}$ also focused on environmental relevance. ${ }^{13}$

The aim of the present study was to establish a comprehensive in vitro inhalation model, enabling the testing of gases, vapors, or aerosols, which might be released during use of a professional hair straightening product or other related consumer products. The following components were of main importance for such an experimental concept:

(1) Handling of the consumer product using a relevant procedure and sampling released vapors, gases, or aerosols.

(2) Basic analytical characterization of gas phase and particulates.

(3) In situ exposure of in vitro or ex vivo human lung tissue or cells in a relevant exposure scenario.

(4) A basic concept for evaluation of testing results by use of relevant positive/negative controls, which have been applied under the same testing regimen.

(5) Establishment of routine applicability.

As a first application, aerosols released during the application of a hair straightener product were subject to an explorative testing. Hair-straightening products are in use by professional hairdressers and thus have a high implication on workplace hygiene. During use, hair straighteners are applied onto the washed hair of the client in a defined procedure, resulting in treating the product on the client's hair at high temperatures $\left(230^{\circ} \mathrm{C}\right)$ by using a flat iron. During this procedure, water and volatile compounds from hair and product evaporate, might undergo chemical reactions, and condense in the environmental air, resulting in a complex aerosol containing a number of substances in the gas and particulate phase. Semi- and low-volatile compounds might be balanced between particulates and gas phase. These aerosols are subject to inhalation by the professional hairdresser and his or her client and thus directly reflect the demand for testing aerosols from product use as described above. Main compounds of the aerosols from hair straightener treatment are known, such as aldehydes, acetone, and siloxanes. Their safety might be assessed based on chemical data base information. ${ }^{14}$ Actually, especially the release of formaldehyde is under discussion as one toxic aerosol compound. ${ }^{15,16}$ However, there is no knowledge about combinatory effects of the complex aerosol mixture or particle composition. Thus, a "nontarget-" driven approach characterizing toxicological behavior on human lung tissue or cells might be a step forward to gain insight into the potential hazard that might arise during application of such products.

With respect to this application, the main five issues for the experimental concept as depicted above would translate into the following:

(1) Use of real strands of hair and application of the product according to a protocol relevant for professional use.

(2) Characterization of the aerosol with respect to known constituents.

(3) Exposure of human lung cells in an air/liquid interface (ALI) culture to generate an unhindered contact of the test aerosol and the cells in an optimized exposure setting (P.R.I.T. ${ }^{\circledR}$ ExpoCube ${ }^{\circledR 17}$ ) and determination of cellular parameters related to cellular toxicity and irritation.

(4) Setup of positive/negative substances, including the following.

- Generation and applicability in the same exposure setup.

- Particle sizes comparable to test aerosol particle sizes.

- Relevance of the compounds for cosmetic products (as far as possible).

- Available data for safety assessment (as far as possible).

(5) Enabling routine applicability with respect to the general setup and use of a commercially available cell line.

The objective of the present study was then to realize an in vitro inhalation model on the basis of the general requirements as above in an exemplary application for the use of a hair straightener product in a worst-case scenario for acute local lung toxicity.

\section{Materials and Methods}

\section{Control substances}

Copper-II-sulfate $\left(\mathrm{CuSO}_{4}\right)$ and sodium dodecyl sulfate (SDS) were purchased from Carl Roth ( $>99 \%$, CP86.1 and $>99.5 \%, 2326.1)$. Lactose was purchased from SigmaAldrich (>99\%, L3750).

\section{Computational fluid dynamics simulations}

Computational fluid dynamics (CFD) studies were conducted using the software package ANSYS Fluent ${ }^{\circledR}$ (ANSYS, Inc.) to evaluate the behavior of flows and particles from aerosol generation. The simulation models comprised a solution procedure for the Navier-Stokes equations with a two-equation turbulence model for the airflow and a Lagrangian frame of reference for particle transport. The particles were treated as nonrotating spheres, and the dynamic behavior was determined by the drag forces from the fluid flow, gravity, inertia forces, and thermophoresis. Due to the small portion of the aerosols in the flow, the impact of the particles on the carrier flow could be neglected. Because of the size of particles, noncontinuum effects such as Brownian motion and a Stokes-Cunningham 
particle drag law (slip correction) were taken into account. For the case with a rotating fan, a moving reference frame with a frozen rotor approach was applied. ${ }^{18}$

\section{Cell culture, exposure, and endpoints}

A549 cells (ATCC; LGC Promochem) were routinely taken from a stock pool and grown in $75-\mathrm{cm}^{2}$ flasks (Dulbecco's modified Eagle's medium [Seromed, Berlin, Germany], 10\% fetal calf serum, and antibiotics). Cells were passaged every 3-4 days. During a cell passage, cells were seeded on microporous membranes $\left(0.4 \mu \mathrm{m}, 1 \mathrm{~cm}^{2}\right.$; BD Falcon). Cells were cultivated on membranes to confluency as inspected by light microscopy. Serum was removed 18 hours before exposure and residual liquid from the apical side of cell monolayers before the exposure. A549 cells were exposed for 60 minutes to test and control substances under ALI conditions using the P.R.I.T. ExpoCube ${ }^{17}$ at exposure flows of $3 \mathrm{~mL} / \mathrm{min}$ per culture at $35^{\circ} \mathrm{C}$ (cells) and $50^{\circ} \mathrm{C}$ (aerosol). Under these conditions, a thermal gradient is created inside the ExpoCube enhancing particle deposition from aerosols during cell exposure by thermophoretic forces. ${ }^{19}$ Directly after or 24 hours after start of treatment of cells, $10 \%$ WST-1 solution (Roche, Mannheim, Germany) was added per well. After 60 minutes of incubation at $37^{\circ} \mathrm{C}, 100 \mu \mathrm{L}$ of the supernatant was transferred into a 96-well plate and measured with a SpectraMax360 plate reader (Molecular Devices) at $450 \mathrm{~nm}$. For interleukin-8 (IL-8) analysis, medium samples were taken 24 hours after cell exposure from the basal side. Cells were kept under ALI conditions after exposure. IL-8 levels were determined with a human IL-8 enzyme-linked immunosorbent assay (ELISA) kit (R\&D Systems, Abingdon, United Kingdom). All procedures were performed according to the manufacturer's instructions.

\section{Aerosol generation from treatment of hair using a commercial hair straightener product}

Strands of natural hair ( 2 g; KAO Germany GmbH, Darmstadt, Germany) were washed with $1 \mathrm{~g}$ of Texapon $(5 \%$ in water; BASF) for 1 minute and dried at $90^{\circ} \mathrm{C}$ using a flat iron (Voss Ultimate). One gram Kerasilk KT (KAO Germany $\mathrm{GmbH}$ ) was applied. The final composition of Kerasilk according to the international nomenclature cosmetic ingredient declaration was (w/w) $1 \%-4.99 \%$ water, $0.1 \%-0.99 \%$ glyoxylic acid, and $<0.1 \%$ of the components cetearyl alcohol, propylene glycol, amodimethicone, fragrance, dehydroxanthan gum, behentrimonium chloride, sodium hydroxide, phenoxyethanol, dipropylene glycol, quaternium-91, isopropyl myristate, cetrimonium methosulfate, trideceth-12, cetrimonium chloride, ethylhexylglycerin, laurdimonium hydroxypropyl hydrolyzed keratin, citric acid, alcohol denat., hydrolyzed silk, yellow 5/C.I. 19140. It was allowed to act on the hair for 15 minutes at room temperature. Strands were predried at $90^{\circ} \mathrm{C}$, dragging the hair 15 times through the flat iron. For aerosol generation, single treated strands of hair were dragged through a flat iron at $230^{\circ} \mathrm{C}$ inside the aerosol box 10 times within about 30 seconds.

\section{Aerosol characterization and chemical analysis}

Scattering light photometry was carried out using a custom-made photometer (Fraunhofer ITEM) and data were transferred to Excel for data analysis. Particle size distributions were analyzed using a wide range aerosol spec- trometer (Mini-WRAS 1371; GRIMM Aerosol Technik) shortly after the generation procedure ( 5 minutes) and before end of the exposure time ( 55 minutes). Mass-based size distributions in the range of 253-21,000 $\mathrm{nm}$ were transferred to Excel for data analysis. 2.4-Dinitrophenylhydrazine (DNPH) cartridges (Supelco No. 21926-U) were used to qualitatively derivatize the carbonyl functionality moiety. Two samples were taken during cell exposure (whole exposure period, prefilter [Pallflex $25 \mathrm{~mm}, 0.2 \mathrm{~L} / \mathrm{min}$ ], half time of the experiment [1 L/min] without prefilter). The filter was weighed to determine aerosol concentrations. Aldehydes and ketones on the filter were derivatized with $1.5 \mathrm{~mL}$ DNPH-solution at $\mathrm{pH} 1$. Following elution with $5 \mathrm{~mL}$ acetonitrile, $20 \mu \mathrm{L}$ of each sample was injected directly into the high-performance liquid chromatography (HPLC) system. LC/ultraviolet-visible conditions: Waters alliance 2695; Waters DAD 996 detection at $355 \mathrm{~nm}$; column Merck Lichrocart $250 \times 4 \mathrm{~mm}, 5 \mu \mathrm{m}$ particle, solvent A: water; solvent B: methanol; gradient $65 \% \mathrm{~B}$ 0-4 minutes $95 \%$ B 18 minutes.

\section{Particle deposition from aerosols}

SDS aerosols were generated inside the aerosol box from SDS solutions in water (Aeroneb; Aerogen) containing $0.1 \%$ sodium fluorescein and dried to dry particle aerosols. Empty microporous membranes were exposed exactly under the conditions of cell exposures and deposited SDS/ Na-fluorescein on cellular membranes was quantified by fluorescence analysis against a standard solution using a microplate fluorescence reader (Gemini; Molecular Devices) at the wavelengths exc. $485 \mathrm{~nm} / \mathrm{em} .525 \mathrm{~nm}$. Deposition rates were calculated using aerosol concentration data derived from concurring gravimetrical analysis of filters.

\section{Statistical analysis}

Statistical analysis was carried out using OriginPro 2017 Software (OriginLab Corporation) and Statistica 13.3 software (TIBCO software). Results from cell exposures and viability or IL-8 data were analyzed using Levene's test on homogeneity of variance, one-way analysis of variance, and a Kruskal-Wallis test. $p$-Values $<0.5$ were considered significant. Dose/response relationships (WST-1, IL-8) were fitted using a best-fit method with $95 \%$ upper and lower confidence intervals.

\section{Results}

\section{Optimized aerosol box for generation and sampling of test aerosols (Aerosol Extraction Box)}

CFD analysis showed that a common cubic box would lead to a significant loss of larger particles as demonstrated by the trajectories of $4 \mu \mathrm{m}$ particles (respiratory fraction) in Figure $1 a^{20}$ Using CFD simulations, several factors (flows, geometry, stirring, temperature) were considered to improve this situation. As a result, a box with a trapezoid shape, a propeller, and a range of applicable flows was constructed. Figure $1 \mathrm{~b}$ shows the relative extraction rates during sampling of aerosol particles under two conditions (original and optimized) from the box. Despite a still higher yield for smaller particles, it documents a much more equilibrated sampling from the optimized Aerosol Extraction Box (AE-Box) regarding inhalation relevant particle sizes between 0.05 and $10 \mu \mathrm{m}$. 

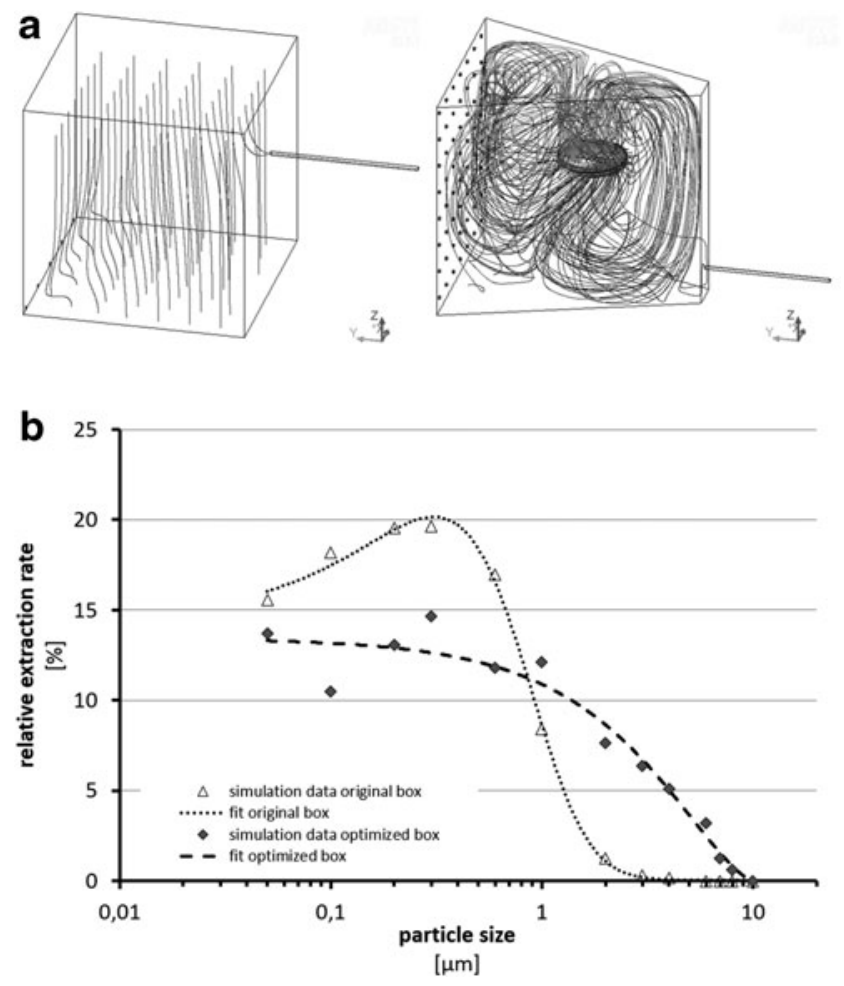

FIG. 1. (a) Design of AE-Box before (left) and after (right) CFD optimization with trajectories of $4.0 \mu \mathrm{M}$ particles as representatives for inhalable aerosols. ${ }^{17}$ (b) Relative particle extraction rates from the AE-Box according to CFD analysis before (original box) and after (optimized box) modification. AE-Box, Aerosol Extraction Box; CFD, computational fluid dynamics.

\section{Experimental setup}

The final experimental setup included the AE-Box with closable openings for manual treatments inside (Fig. 2) connected to clean air $\left(40 \% \mathrm{rH} / 22^{\circ} \mathrm{C}\right)$ at environmental pressure. TENAX filter and DNPH samples were taken off-line. Cell exposure was conducted using the P.R.I.T. ExpoCube using thermophoresis conditions. Using this mode of operation, a thermal gradient of $15^{\circ} \mathrm{C}$ was applied between the test aerosol and cellular surface to facilitate particle deposition from the aerosols onto the cellular surface. The test aerosol was conducted from the AE-Box through a light scattering photometer and through the ExpoCube toward the particle spectrometer for particle size distribution measurements.

\section{Selection of positive and negative compounds}

Lactose, $\mathrm{CuSO}_{4}$, and SDS were chosen as negative and positive controls, respectively. Lactose is largely used in the food and pharmaceutical industry as a carrier or filling, also with a relevance for inhalable drugs. It is not harmful and no adverse effects are known despite suffering from lactose intolerance in individuals. ${ }^{14}$

$\mathrm{CuSO}_{4}$ is used as a herbicide, fungicide, and pesticide and has other applications based on color, antiseptic properties, or hygroscopicity (pates, dyes, analytical chemistry). It is classified as irritant in humans and is harmful on inhalation or ingestion. ${ }^{21-25}$ Epidemiological knowledge on inhalation exposure of men from $\mathrm{CuSO}_{4}$ is based on its use in vineyard spraying. ${ }^{25-27}$ Known effects include severe eye irritation, irritation of respiratory tract, severe irritation of mucous membranes, congestion, and lung inflammation, as well as degenerative changes in the lung. ${ }^{28-30}$ SDS has applications in household products for cleaning and hygiene based on its

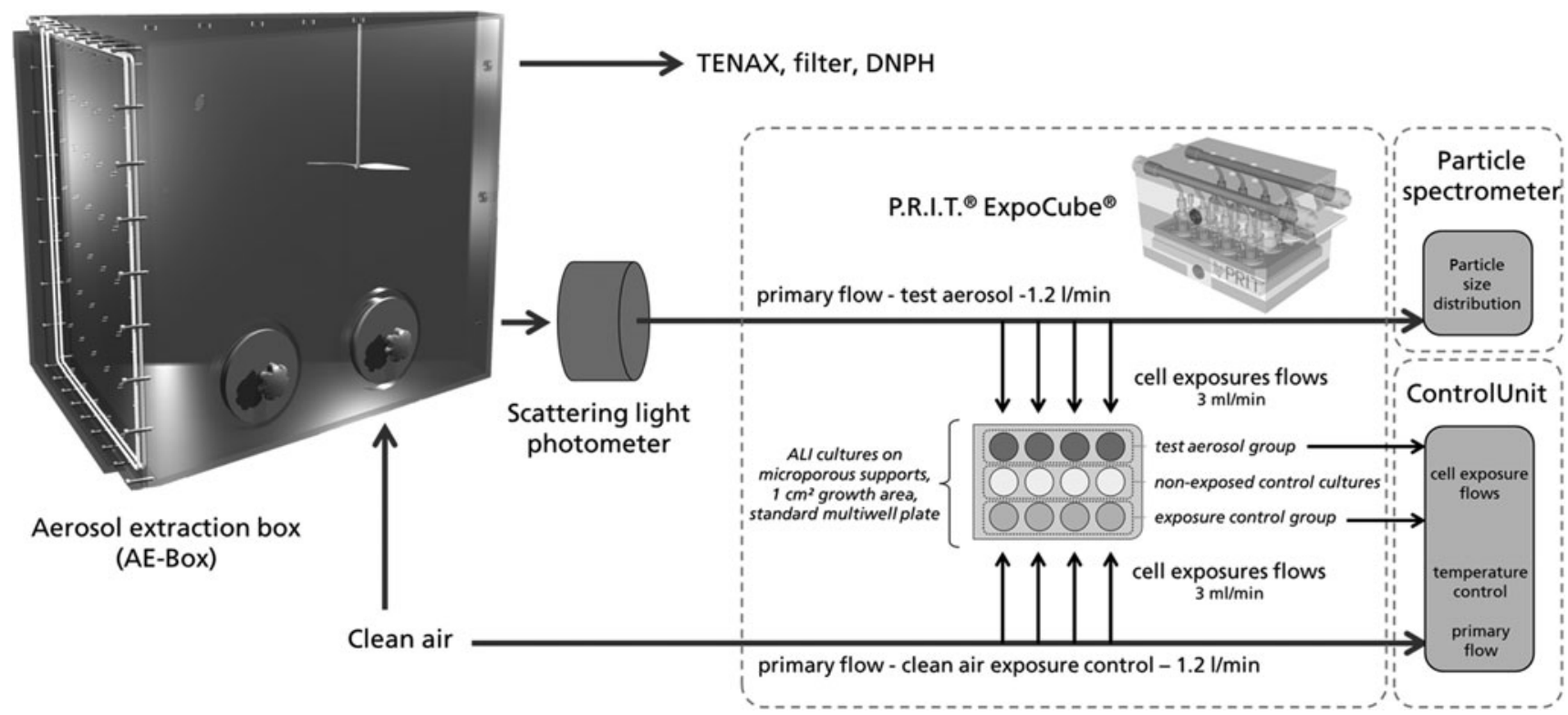

FIG. 2. Experimental setup, including AE-Box, scattering light photometer, P.R.I.T. ${ }^{\circledR}$ ExpoCube ${ }^{\circledR}$ cell exposure device, and particle spectrometer. Exposures were carried out under thermophoretic conditions inside the ExpoCube by application of a thermal gradient $\left(15^{\circ} \mathrm{C}\right)$ between aerosol and cells, enhancing the particle deposition on the surface of the A549 ALI cultures. ALI, air/liquid interface. 
amphiphilic properties. It is also in use in cosmetic products. It is harmful on ingestion and causes serious eye, skin, and respiratory irritation. ${ }^{31}$

\section{Aerosol generation from positive/negative compounds}

The generation and exposure process included nebulization of aqueous test compound solutions and drying of the droplet aerosol inside the aerosol box. By variation of compound concentrations and the aerosol generation rate, mean particle sizes and aerosol concentrations could be adjusted independently. Resulting particle sizes are shown in Table 3.

\section{Cell exposure controls}

The exposure process using the P.R.I.T. ExpoCube includes concurrent exposure of three groups in the same multiwell plate. ${ }^{17}$ A nonexposure group is maintained under the same conditions as the other groups (temperature, transport of the plate, etc.) but without exposure airflow. A clean air exposure control is exposed to clean air only and the test aerosol group is exposed toward the test aerosol at the same conditions (flows, temperature) as the clean air exposure control. "Empty box" control exposures were conducted from the empty AE-Box simulating the aerosol generation process to capture possible adverse effects.

Viability data from nonexposure cells after a 1-hour experimental period are shown in Figure 3a. They demonstrate constant values for secretions of IL-8 (mean $174.69 \mathrm{pg} / \mathrm{mL}$ ) and optical density (O.D.) readings from the WST-1 assay (mean 0.948 O.D.) throughout the experimental period of 125 single experiments. Figure $3 \mathrm{~b}$ represents correspondent results from clean air exposure controls. The validity level ${ }^{17}$ of $70 \%$ with respect to viability was met without exception (mean of $94.08 \%$ ) throughout the experimental period. IL-8 secretions were also constant over the whole experimental period with a mean level at $153 \%$ of nonexposure controls, displaying a typical increase induced only by the flow of clean air over the surface of ALI cells (unpublished data).

Results from empty box control exposures are shown as a part in Figures 6 and 7 and were comparable to clean air control exposures.

\section{Cell exposures toward control substances}

Viability data from dry particle lactose aerosols (5-948 $\mu \mathrm{g} / \mathrm{m}^{3}$ ) (Fig. 4a) were comparable to clean air exposure controls up to a concentration of $200 \mathrm{mg} / \mathrm{m}^{3}$ with a slight, nonsignificant indication of toxicity (WST-1) at highest concentrations. In contrast to this, exposures toward lactose induced a moderate concentration-dependent increase of IL-8 secretion at $100 \mathrm{mg} / \mathrm{m}^{3}$ and higher (Fig. $4 \mathrm{~b}$ ).

Exposure to dry particle aerosols from SDS $\left(0.17-700 \mathrm{mg} / \mathrm{m}^{3}\right)$ (Fig. 4b) resulted in a highly reproducible dose-dependent toxic response starting at $30 \mathrm{mg} / \mathrm{m}^{3}$. At lowest SDS concentrations tested $\left(0.17-1.75 \mathrm{mg} / \mathrm{m}^{3}\right)$, a $10 \%$ reduction of viability was also observed. IL-8 secretions were increased in comparison to clean air controls starting at the lowest aerosol concentrations tested $\left(0.15 \mathrm{mg} / \mathrm{m}^{3}, 175 \%\right.$ of exposure control) (Fig. 4b). The increase of IL-8 secretions turned into concentration-dependent decreases at toxic SDS concentrations $\left(\geq 60 \mathrm{mg} / \mathrm{m}^{3}\right)$.

Viabilities of A549 cells were decreased dose dependently following $\mathrm{CuSO}_{4}$ dry particle aerosol exposures at $30 \mathrm{mg} / \mathrm{m}^{3}$ and higher (Fig. 4e). IL-8 secretions increased concentration dependently ( $\geq 10 \mathrm{mg} / \mathrm{m}^{3}$, Fig. 4f). This increase remained also present at concentrations inducing strong cellular toxicity $\left(\geq 100 \mathrm{mg} / \mathrm{m}^{3}\right)$.

\section{Aerosol generation from treatment of hair using a commercial hair straightener product}

The procedure developed for generation of aerosols from a commercial hair straightener product considered the real use of the product (Fig. 5) with natural strands of hair according to the manufacturer's advice for application, including prewashing, predrying, and use of original flat irons at the recommended temperatures $\left(90^{\circ}\right.$ predrying, $230^{\circ} \mathrm{C}$ treatment). One, 5, or 10 treatments of single strands of hair were conducted inside the AE-Box sequentially during one cell exposure experiment.

\section{Characterization of aerosol from a commercial hair straightener product}

Glyoxylic acid, formaldehyde, and particle characteristics were analyzed from aerosols after hair treatments. Results of
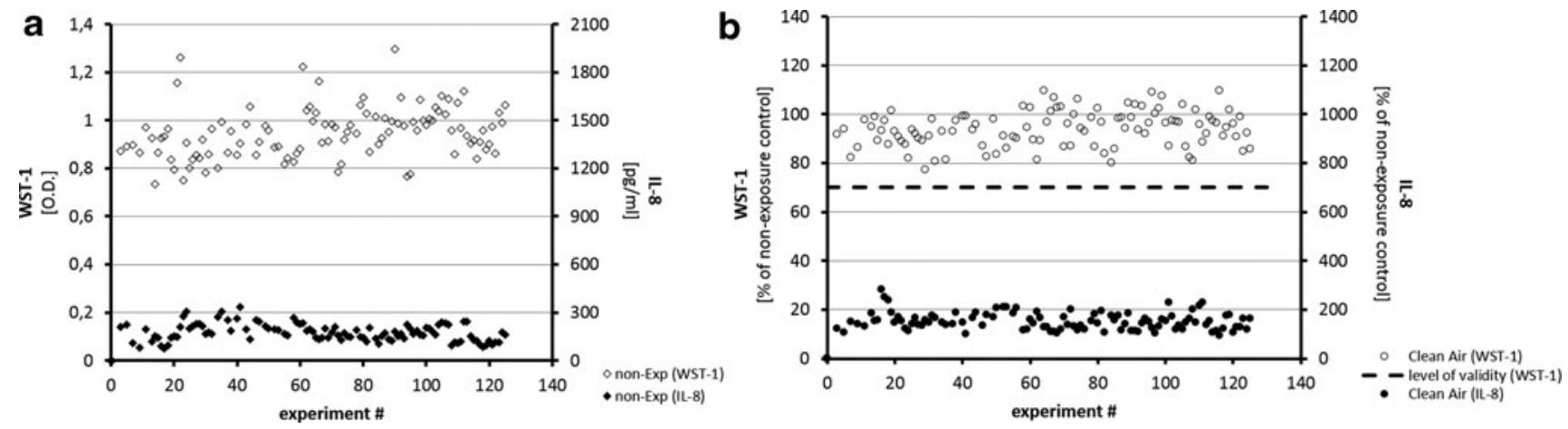

FIG. 3. (a) Chronological plot of data from nonexposure controls over the time of study. Mean \pm SD for WST-1 data was 0.948 O.D. $\pm 0.106(n=107)$, mean \pm SD for IL-8 data was $174.69 \pm 53.53 \mathrm{pg} / \mathrm{mL}(n=107)$. (b) Chronological plot of data from clean air controls over the time of study (percent age of nonexposure controls). Mean \pm SD for WST-1 data was $94.08 \% \pm 7.24 \%(n=107)$, mean \pm SD for IL-8 data was $153.03 \% \pm 35.81 \%(n=107)$. IL-8, interleukin-8; O.D., optical density; SD, standard deviation. 

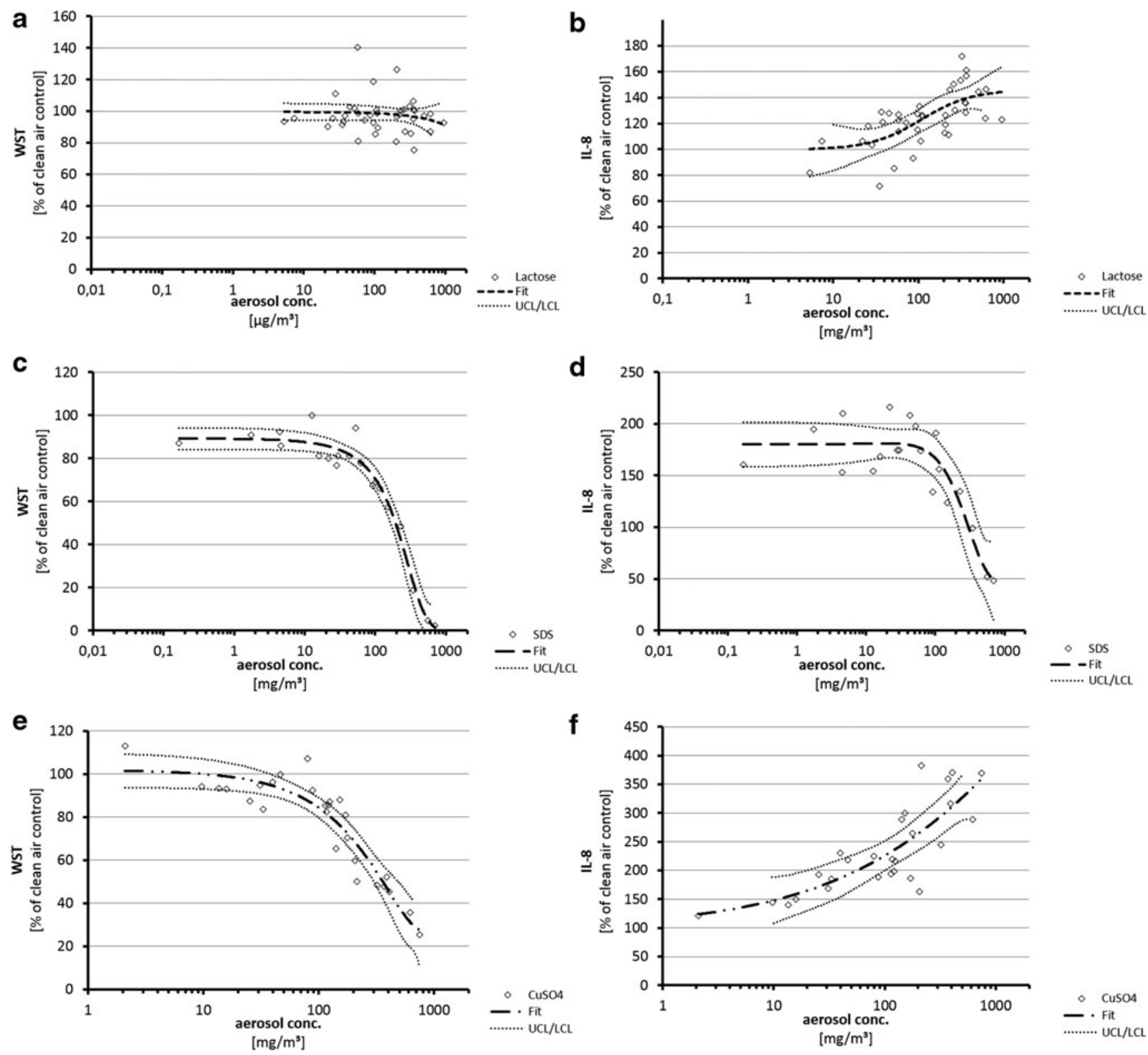

FIG. 4. Viability and IL-8 secretion data from A549 cells after exposure to varying dry aerosol concentrations of control substances. Dots represent results from independent single-exposure experiments. Fitting was applied according to a best-fit method with 95\% confidence intervals. (a) Lactose aerosols, viability; (b) lactose aerosols, IL-8 secretion; (c) SDS aerosols, viability; (d) SDS aerosols, IL-8 secretion; (e) copper sulfate, viability; (f) copper sulfate, IL-8 secretion. SDS, sodium dodecyl sulfate.

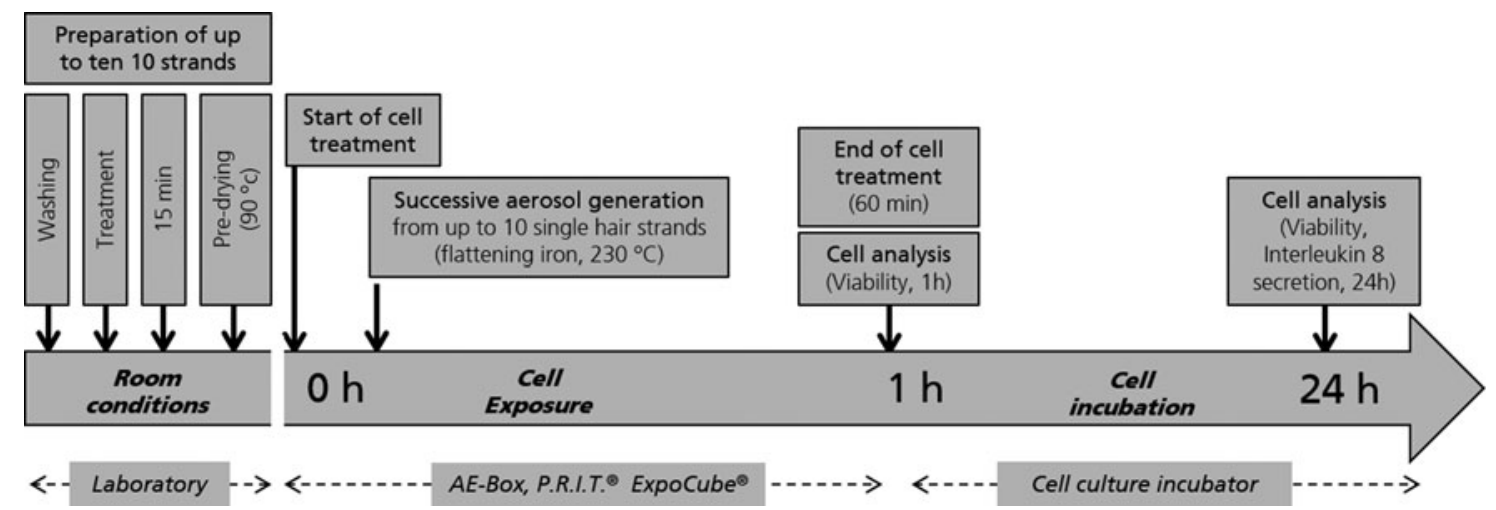

FIG. 5. Resulting testing procedure for a consumer relevant generation of aerosols from hair straightener and concurrent ALI exposure of human lung cells to native aerosols. 


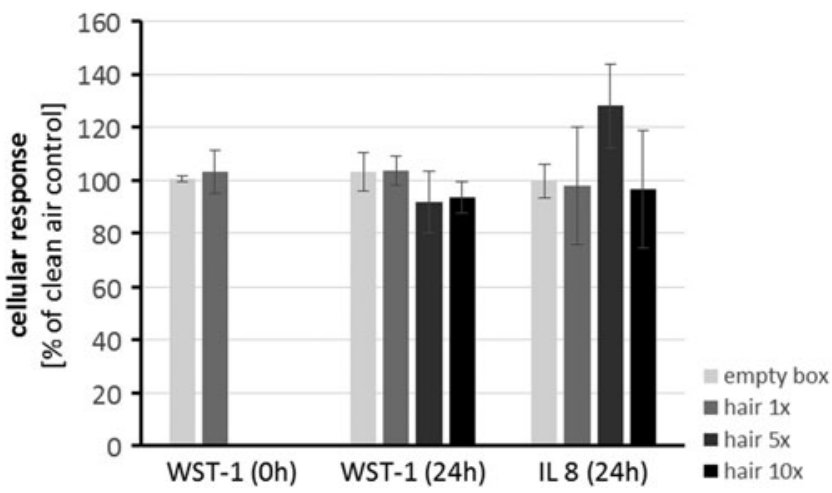

FIG. 6. Effects of aerosol generated from 1, 5, or 10 hair straightener treatments on A549 cells. Results from viability (WST-1) and interleukin secretion (IL-8) measurements. Data are expressed as mean \pm standard deviation; $n=3$ for 0 -hour measurements and hair $1 \times$ treatments (24 hours), $n=4$ for hair $5 \times$ and hair $10 \times$ treatments, $n=9$ for empty box (24 hours) exposures. Statistical analysis of experimental groups was carried out by analysis of variance (WST-1 [0 hours] measurements and WST-1 [24 hours]) and a Kruskal-Wallis test (IL-8 [24 hours]). Experimental groups were found not to be statistically different $(p>0.05)$.

the aerosol analysis are shown in Table 1. Glyoxylic acid, formaldehyde, and particles increased with the amount of sequential treatments and reached $31 \mathrm{mg} / \mathrm{m}^{3}$ glyoxylic acid, $13 \mathrm{mg} / \mathrm{m}^{3}$ formaldehyde, and $192 \mathrm{mg} / \mathrm{m}^{3}$ particles at highest concentrations. Whereas concentrations increased about a factor of 5 from single hair treatments to sequential treatment of 5 hairs in a row, they did not quantitatively increase with a factor of 2 from 5 to 10 hair treatments due to high concentration effects (coagulation, loss of large particles). Ten hair treatments resulted therefore in the highest applicable aerosol concentrations in this experimental setup, according to a "worst-case scenario." Particle size distributions as analyzed using the Grimm MiniWRAS monitor are shown in Table 3. Mean particle sizes were below $1 \mu \mathrm{m}$ and were covered by the particle sizes of the positive and negative controls.

\section{Cell exposures toward aerosol released from a hair straightener product}

A549 cells were exposed during 60 minutes toward aerosols from hair treatments. Following this, they were analyzed 24 hours after start of the treatment with respect to viability (tetrazolium salt assay WST-1) and secretion of IL-8 into the culture medium (ELISA). After exposure to aerosols from single hair treatments, cell viability was also analyzed directly after end of the exposure ( 0 hour). Figure 6 shows the results in comparison to control exposures from the empty exposure box. Exposures using single hair treatments did not result in different viabilities or IL-8 secretions in comparison to empty box directly after exposures (0 hour) or 24 hours later ( 24 hours). Exposures to aerosols from 5 or 10 hair treatments induced a slight, not statistically significant, reduction of cellular viability to $90 \%$ of empty box exposures. IL-8 secretions from cells after exposure toward aerosols from hair treatments were comparable with IL-8 secretions from empty box exposures for 1 hair treatment and
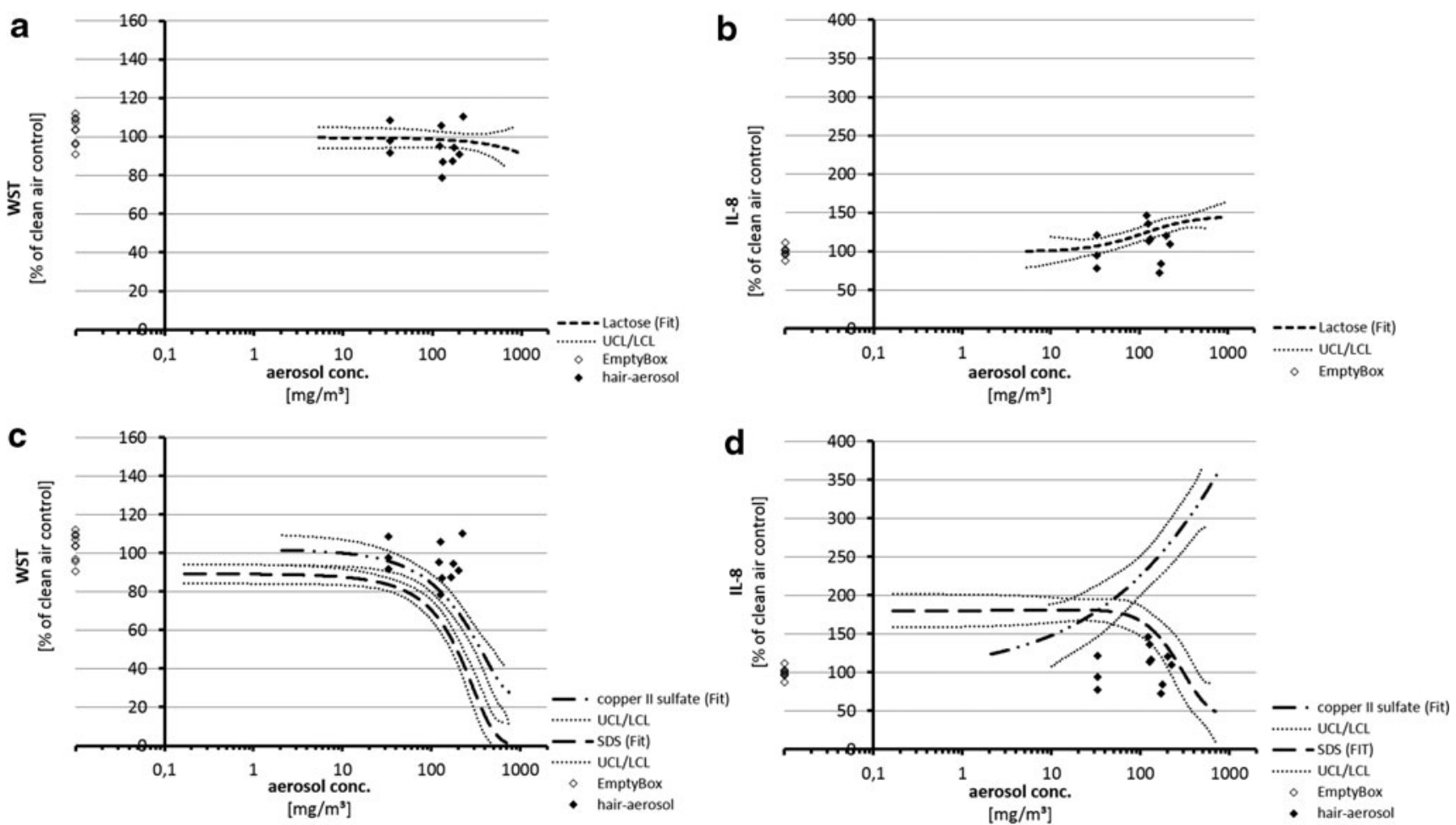

FIG. 7. Comparison of effects from exposures to aerosols from hair treatments and empty box, negative or positive controls on a concentration-based dose metric. (a) Lactose aerosols and aerosol from hair treatments, viability. (b) Lactose aerosols and aerosol from hair treatments, IL-8 secretion. (c) SDS and copper sulfate aerosols and aerosol from hair treatments, viability. (d) SDS and copper sulfate aerosols and aerosol from hair treatments, IL-8 secretions. 
Table 1. Results of Chemical Analysis of Aerosol from Hair Straightener Use After Application of 1, 5, or 10 Hair Treatment Inside the Aerosol Exposure BoX

\begin{tabular}{|c|c|c|c|c|c|c|c|c|c|c|c|c|}
\hline & \multicolumn{4}{|c|}{ One treatment } & \multicolumn{4}{|c|}{ Five treatments } & \multicolumn{4}{|c|}{ Ten treatments } \\
\hline & $\begin{array}{c}\text { Mean } \\
(\mu g / 216 L)\end{array}$ & $\begin{array}{c}S D \\
(\mu g / 216 L)\end{array}$ & $\begin{array}{c}\text { Mean } \\
\left(\mathrm{mg} / \mathrm{m}^{3}\right)\end{array}$ & $\underset{\left(m g / m^{3}\right)}{S D}$ & $\begin{array}{c}\text { Mean } \\
(\mu g / 216 L)\end{array}$ & $\begin{array}{c}S D \\
(\mu g / 216 L)\end{array}$ & $\begin{array}{c}\text { Mean } \\
\left(\mathrm{mg} / \mathrm{m}^{3}\right)\end{array}$ & $\begin{array}{c}S D \\
\left(m g / m^{3}\right)\end{array}$ & $\begin{array}{c}\text { Mean } \\
(\mu g / 216 L)\end{array}$ & $\begin{array}{c}S D \\
(\mu g / 216 L)\end{array}$ & $\begin{array}{c}\text { Mean } \\
\left(\mathrm{mg} / \mathrm{m}^{3}\right)\end{array}$ & $\begin{array}{c}S D \\
\left(m g / m^{3}\right)\end{array}$ \\
\hline Glyoxylic acid & 1193.75 & 285.61 & 5.53 & 1.32 & 3984.67 & 1088.59 & 18.45 & 5.04 & 6703.75 & 2343.54 & 31.04 & 10.85 \\
\hline Formaldehyde & 727.50 & 123.23 & 3.37 & 0.57 & 1868.67 & 150.00 & 8.65 & 0.69 & 2807.00 & 473.92 & 13.00 & 2.19 \\
\hline Particles & 7177.08 & 697.48 & 33.23 & 3.23 & 27500.00 & 901.85 & 127.31 & 4.18 & 41475.00 & 5342.52 & 192.01 & 24.73 \\
\hline
\end{tabular}

$\mathrm{SD}$, standard deviation.

for 10 hair treatments and slightly but not statistically significantly induced for 5 hair treatments.

\section{Comparison of exposure effects from control substances and aerosol from hair treatments based on aerosol concentration}

Figure 7 compares results from cell exposures to aerosols from hair treatments with results from negative (Fig. 7a, b) and positive substances (Fig. 7c, d) on a concentration-based dose metric. Figure $7 \mathrm{~b}$ displays that the slight increase of IL-8 secretion after exposure to aerosols from five hair treatments was congruent with the induction of IL-8 after exposure to lactose in the same concentration range $\left(100-150 \mathrm{mg} / \mathrm{m}^{3}\right)$. Figure $7 \mathrm{c}$ documents that cellular viabilities after exposures to positive controls were significantly reduced at concentrations comparable to highest aerosol concentrations from hair treatments where the respective cell viabilities did not show impairment $\left(100-200 \mathrm{mg} / \mathrm{m}^{3}\right)$. After exposure to positive controls, IL- 8 secretion induced in concentration ranges was also applied with aerosols from hair treatments (30$200 \mathrm{mg} / \mathrm{m}^{3}$ ) where the respective cell exposures to aerosols from hair treatments did not or only very slightly induce IL-8 secretion (Fig. 7d).

\section{Particle deposition}

Particle deposition experiments were carried out using dry particle SDS aerosols. Deposition rates were $29.43 \%$ for the smallest particle size $(446 \mathrm{~nm})$ and $43.00 \%$ resp. $47.78 \%$ for the larger particles (923 or $1707 \mathrm{~nm}$ ) (Table 2). The variability of particle deposition with respect to distribution of particles over the four concurrent technical replicates in the P.R.I.T. ExpoCube was smaller than $10 \%$ throughout all experiments. Also, the relative distribution of particles over the four technical replicates was homogeneous. These results were compared with historical results from our laboratory using the ExpoCube in similar experimental setups with different kinds of dry particle aerosols (Fig. 8). The present results were in good agreement with these data. A cubic fitting was applied using all these data and is also depicted in Figure 8 with upper and lower confidence limits (95\%). This fitting was used to calculate the relevant deposition rate for test aerosols such as the aerosol from hair treatments on the basis of mean particle size (Table 3).

\section{Comparison of exposure effects from control substances and aerosol from hair treatments based on cellular surface loads}

Results from particle deposition experiments (Tables 2 and 3 and Fig. 8) and concentration-based dose/response relationships (Fig. 7) allowed the comparison of exposure effects from control substances and aerosol from hair treatments based on the cellular surface load (Fig. 9). Due to an only very small dependency of the particle deposition rate from the particle size as evaluated by particle deposition experiments and validated by historical values (Fig. 8), the relative dose/response between the different test items does not differ significantly from dose/response curves based on aerosol concentrations (Fig. 7).

\section{Discussion}

An in vitro test system was developed for aerosols that might be produced during use of consumer products. As a first example, a hair care product was chosen, which is used as a hair straightener by professional hairdressers. During use, the product is applied on the hair of the client and aerosol is generated in a considerable amount during the

Table 2. Results from Particle Deposition Measurements Using the P.R.I.T. ExpoCube Under Thermophoresis Conditions with Sodium Dodecyl Sulfate Aerosols and Different Aerosol Mean Particle Sizes

\begin{tabular}{|c|c|c|c|c|c|c|c|c|}
\hline \multirow{2}{*}{$\begin{array}{l}\text { SDS concentrations } \\
(\%)\end{array}$} & \multirow{2}{*}{$\begin{array}{l}\text { Particle } \\
\text { size }(\mathrm{nm})\end{array}$} & \multicolumn{4}{|c|}{ No. of technical replicate in ExpoCube ${ }^{\circledR}$} & \multirow[b]{2}{*}{ Mean } & \multirow[b]{2}{*}{$S D$} & \multirow{2}{*}{$\begin{array}{c}S D \\
(\% \text { of mean })\end{array}$} \\
\hline & & 1 & 2 & 3 & 4 & & & \\
\hline 0.1 & 446 & 30.13 & 27.30 & 32.29 & 28.01 & 29.43 & 2.26 & 7.66 \\
\hline 2.0 & 923 & 44.16 & 39.78 & 45.65 & 42.39 & 43.00 & 2.52 & 5.87 \\
\hline 10.0 & 1707 & 46.22 & 51.03 & 48.42 & 45.45 & 47.78 & 2.50 & 5.24 \\
\hline \multirow[t]{2}{*}{ Distribution (\%) } & Mean & 100.80 & 96.91 & 105.50 & 96.79 & & & \\
\hline & SD & 8.54 & 8.12 & 6.79 & 6.47 & & & \\
\hline
\end{tabular}

SDS, sodium dodecyl sulfate. 
Table 3. Mean Particle Sizes of the Different Aerosols Used in This Study and Deposition Rates Calculated from the Deposition Calibration Curve as Depicted in Figure 8

\begin{tabular}{|c|c|c|c|c|c|}
\hline \multirow[b]{2}{*}{ Aerosol } & \multirow[b]{2}{*}{ Generated from sol. (\%) } & \multicolumn{3}{|c|}{ Particle size $(\mathrm{nm})$} & \multirow{2}{*}{$\begin{array}{c}\text { Deposition rate } \\
(\%)\end{array}$} \\
\hline & & $M W$ & $S D$ & $\mathrm{n}$ & \\
\hline Lactose & 10.0 & 1401 & 144 & 7 & 34.2 \\
\hline Lactose & 20.0 & 1765 & 311 & 6 & 43.9 \\
\hline $\mathrm{CuSO}_{4}$ & 5.0 & 904 & 53 & 4 & 36.2 \\
\hline $\mathrm{CuSO}_{4}$ & 10.0 & 1145 & 2 & 6 & 35.4 \\
\hline SDS & 0.1 & 446 & 86 & 6 & 28.8 \\
\hline SDS & 2.0 & 923 & 139 & 5 & 36.1 \\
\hline \multirow[t]{2}{*}{ SDS } & 10.0 & 1707 & 204 & 6 & 41.1 \\
\hline & $\begin{array}{l}\text { point of analysis during } \\
\text { cell exposure }\end{array}$ & & & & \\
\hline One hair treatment & Start & 796 & 49 & 6 & \\
\hline One hair treatment & End & 565 & 42 & 6 & \\
\hline One hair treatment & Mean & 680 & & & 35.3 \\
\hline Five or 10 hair treatments & Start $^{\mathrm{a}}$ & 953 & & & \\
\hline Five or 10 hair treatments & End & 850 & 86 & 3 & \\
\hline Five or 10 hair treatments & Mean & 901 & & & 36.19 \\
\hline
\end{tabular}

${ }^{a}$ Calculated value from end measurement. Particle size could not be analyzed directly due to high concentration.

$\mathrm{CuSO}_{4}$, copper-II-sulfate.

following heating procedure. This raises the question for relevance of inhalation toxicology from the perspective of occupational safety. As reviewed in the Introduction, risk assessment as it is typically performed for regulatory purposes such as chemical registration and authorization under Registration, Evaluation, Authorisation and Restriction of Chemicals, ${ }^{32}$ authorization of active substances as biocides under Biocidal Products Regulation, ${ }^{33}$ and compounds used in cosmetics under cosmetics product regulation ${ }^{2}$ is impossible here due to the physicochemical behavior of the aerosol, lacking inhalation toxicology data and unknown toxicology of mixtures.

The aim of the present study was to generate relevant aerosols as close as possible to the real situation, expose human

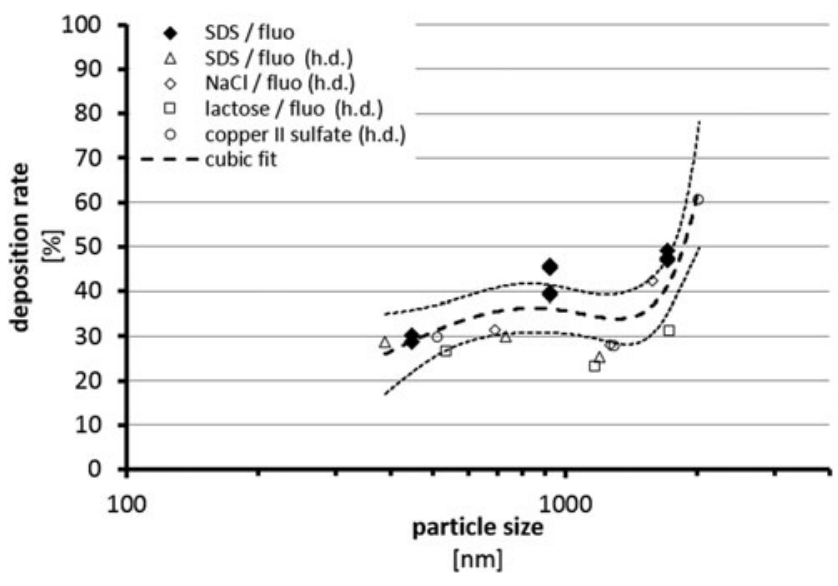

FIG. 8. Plot of the data from size distribution measurements against historical data (h.d.) from our laboratory using the P.R.I.T. ExpoCube in different test setups under thermophoresis conditions. Fitting of the data resulted in a calibration curve used for calculation of particle deposition rates from aerosol concentrations. cells toward these aerosols, measure biological effects of exposure, and include a concept that might indicate the relevance of detected effects for the human inhalation situation. As a first step, effects of interest are focused on acute local effects in the lung in a worst-case scenario.

To enable a relevant exposure situation, the method for generation of the aerosol from hair treatments included all steps executed by the hairdresser. The aerosol was generated in a box optimized to sample under conditions as representative as possible for in vitro testing. As depicted in Figure 1 and according to results from CFD modeling, the extraction rate of aerosol particles from the optimized AE-Box was much more homogenous for different particle sizes than from a standard cubic box. Hence, a more representative effect of different particle sizes can be derived rather than emphasizing effects of smaller particles by a potentially higher extraction rate using a common cubic box. Also, by starting the cell exposure procedure already during generation of the aerosol (Fig. 5), a capture of native, "fresh" aerosol particles is enabled, which especially might have significance for inhalation toxicology.

The delivery of particles from the AE-Box to the cells was validated by use of one of the positive controls in an analytical experimental setting. Mixtures of SDS and fluorescein sodium were nebulized. Evaporation within the AE-Box resulted in dry particle aerosols, which were applied under the conditions of cell exposures to culture membranes. Fluorescence analysis from the culture wells enabled validation of the deposition and exact deposition rates could be derived for different particle sizes covering the size ranges of the test aerosols from hair treatments (Tables 2 and 3). By comparing the present results from deposition analyses with historical data (Fig. 8), a good consistency was found. Data documented high deposition rates around $35 \%$, which were relatively independent on particle sizes between 400 and $1600 \mathrm{~nm}$. Larger particles resulted in higher deposition rates by additional gravitational effects with increasing particle sizes. On one hand, these results 

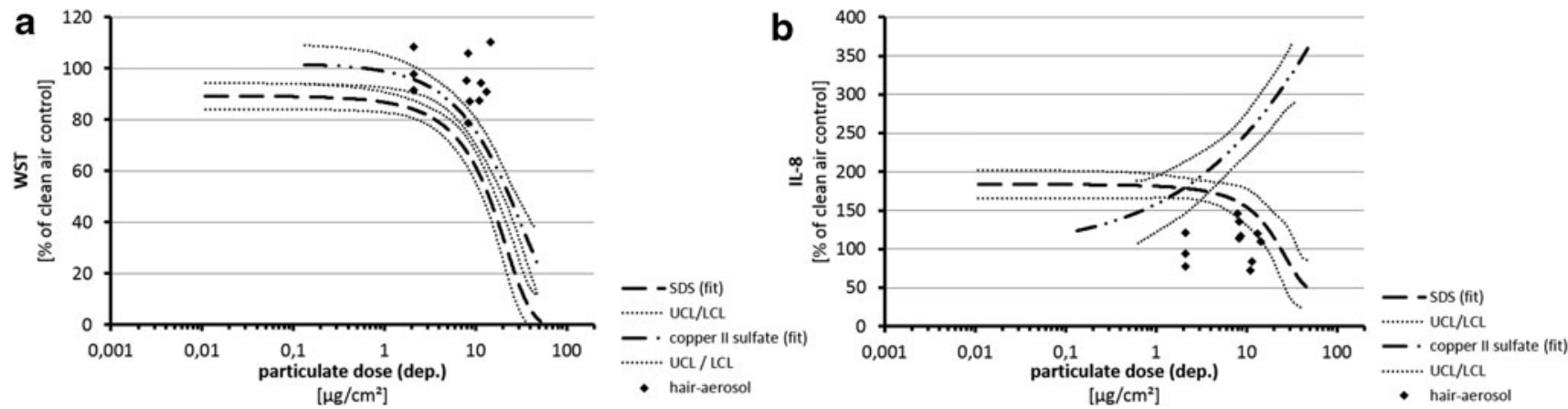

FIG. 9. Comparison of effects from exposures to aerosols from hair treatments and positive controls on a cellular surface load-based dose metric. (a) SDS and copper sulfate aerosols and aerosol from hair treatments, viability. (b) SDS and copper sulfate aerosols and aerosol from hair treatments, IL-8 secretions.

validate the delivery of particles onto the cellular surfaces during exposure, and on the other hand they were used to quantify exactly the deposited amount during exposure from concentration data to evaluate the cellular surface particle load.

With respect to the choice of positive/negative substances, both gaseous and particulate airborne compounds had principally been suitable due to the nature of the aerosol generated from hair treatment as being composed of a complex gaseous phase and a complex particulate phase. For two main reasons it was decided in this study to focus on particulate aerosols as controls. In the first instance and from the point of aerosol characteristics, more information is present about the composition of the gaseous phase of the aerosol from hair treatment than about the particulate phase. Main components of the gaseous phase such as glyoxylic acid or formaldehyde can be chemically analyzed and their potential toxicity can be estimated by safety assessment procedures. Since its quantitative and also qualitative composition is largely unknown, this is not true for the particulate phase of the test aerosol. Therefore, more information is needed on the behavior of comparable test particles in the experimental setup used as a basis for classification of the total aerosol. Second, the experimental handling of airborne particles demands for a much higher control of experimental parameters such as the basic experimental concept, flows, fluid mechanics, particle sizes, and losses. Therefore, a control of the behavior of particles in an experimental aerosol setup is highly valued for its characterization.

To identify the cellular susceptibility and sensitivity toward relevant effects from inhalable compounds, the in vitro inhalation model was characterized using three control substances. Lactose was used as negative substance. Lactose is widely in use as carrier in pharmacology and also in inhalation relevant applications. SDS is a known mild toxicant and irritant, and $\mathrm{CuSO}_{4}$, both of which were applied as positive controls. Knowledge about human effects of these substances during inhalation is limited, although $\mathrm{CuSO}_{4}$ is clearly known to have relevant effects, based on epidemiologic data from vineyard workers. The so-called Bordeaux-solution is in use as a fungicide and is made responsible for effects on inhalation such as interstitial pulmonary lesions and fibro-hyaline nodules very similar to those found in silicosis. ${ }^{28}$ Hence, both substances can be classified as positive controls in this in vitro inhalation model both for induction of cell toxicity and irritancy.
With respect to the biological test system, a compromise had to be found between availability and applicability in routine testing and a maximum relevance for the real situation in human. A549 cells represent a robust test system with an origin from the alveolar region of the human lung. ${ }^{34,35}$ As far as it is deducible from the results of this study, it seems reasonable using this single-cell system to reflect basic principles of biological effects as they were reproducibly induced with high significance for the positive and negative control substances.

As an endpoint for cell toxicity, a tetrazolium salt-based assay (WST-1) was carried out. Since the establishment of these assays for in vitro studies by Mosmann, ${ }^{36}$ they have been widely in use because of reproducibility, simple use, and meaningfulness of results by representing pathways of the cellular mitochondrial metabolism. ${ }^{37}$ IL- 8 secretion by A549 cells was chosen as a parameter for induction of irritative changes. IL- 8 is a well-known chemokine involved in molecular pathways connected to irritative responses toward substances. ${ }^{38,39}$ However, if more detailed information about cellular metabolism, pathways of toxicity, or adverse outcome pathways (AOPs) is under interest for a deeper toxicological characterization, or to cover multiple molecular initiating events (MIEs) ${ }^{40}$ under discussion, the application of primary cells and endpoints such as gene expression analysis, metabolomics, or other methods might be applied in the future. This might also be carried out taking into account specific MIEs of known constituents of the aerosol. Although there is no scientific consensus on the AOP and MIEs of formaldehyde, this could be considered, for example, by analysis of DNA adducts, DNA-DNA or DNA-protein crosslinks in the present case. ${ }^{41}$

Exposures toward control substances in this inhalation model induced distinct effects between positive and negative substances with respect to cellular cytotoxicity. Whereas lactose did not induce significant cytotoxic effects up to the highest concentration tested (near $1 \mathrm{~g} / \mathrm{m}^{3}$ ), dry particle aerosols from SDS or copper sulfate induced dose-dependent toxic effects at a tenth of this concentration or below. With respect to the induction of IL-8, three different characteristics were found. For lactose, a slight concentration-dependent increase was found starting at concentrations of about $50 \mathrm{mg} / \mathrm{m}^{3}$ up to $140 \%$ of control exposures (clean air) at the highest lactose concentration. SDS already induced IL-8 at the lowest concentration tested (below $1 \mathrm{mg} / \mathrm{m}^{3}$ ) to $175 \%$ compared to clean air exposures with a constant, concentration-independent increase 
but only at nontoxic concentrations. In contrast to this, copper sulfate induced concentration-dependent increase of IL-8 up to values near $400 \%$ of control, but independently on copper sulfate toxicity.

From these results we conclude that the basic in vitro inhalation model had been successfully established. Particles are delivered from the aerosol phase to the cellular surface at a substantial and reproducible rate and the susceptibility, responsiveness, and specificity of cellular response could be shown by use of relevant negative and positive control substances.

The generation of aerosols from hair treatments could be carried out under conditions very close to the real application of the hair straightener product by professional hairdressers. Using real hair, all steps in the procedure could be included. Moreover, by carrying out the procedure with sequential hair treatments, three scenarios were introduced, including the processing of 1,5 , or 10 strands of hair in a row. Results from chemical analysis of glyoxylic acid, formaldehyde, and particle mass documented that the aerosol concentrations increased reproducibly with the increasing number of hair treatments in a row in this experimental setup. However, since concentrations did not double from the 5 to the 10 hair scenario, it was concluded that these high concentrations (near $200 \mu \mathrm{g} / \mathrm{m}^{3}$ ) already enabled particle interactions, and thus, the 10 hair scenario was defined as the highest technical possible concentration with relevance for reality in a worstcase scenario.

Using A549 cells in this in vitro inhalation model, small, non-significant, changes were found after exposure toward aerosols from 5 and 10 hair treatments with respect to viability. IL-8 secretion was induced only after exposure toward hair aerosol in the five hair strands scenery. To evaluate the relevance of these results, they were quantitatively evaluated on a concentration and cellular surface load basis (Figs. 7 and 9). Viability data show that effects from aerosols from hair treatments were comparable to the negative control. However, by the reduction of viability after exposure to SDS or copper sulfate at $100 \mathrm{mg} / \mathrm{m}^{3}$ resp. $10 \mu \mathrm{g} / \mathrm{cm}^{2}$, a sensitivity of the test system to display potential toxicity at these dose levels is demonstrated. This was true also for IL-8 secretion, where a strong induction from the positive controls was found but less or no induction by aerosols from hair treatments in the same dosage ranges. Moreover, the nonsignificant induction of IL- 8 after exposure of cells to the five hair scenario was exactly covered by the IL- 8 response after exposure of cells to the negative control lactose.

From these results, the relevance for occupational exposure may be discussed. Lactose, recognized as a substance not likely to constitute any significant toxicological hazard to man, ${ }^{42}$ induced low effects in highest dosages. They may possibly be characterized as pure physical "particle" effects at high cellular surface loads without substance specificity. However, biological effects from high doses of lactose were also found in other studies in vitro in a human bronchial lung cell line ${ }^{43}$ and in vivo in rats by inhalation. ${ }^{44}$ The respective dosages of about $10 \mu \mathrm{g} / \mathrm{cm}^{2}$ on the cellular surface in this study are high values for an acute toxicity scenario. On the basis of a $60 \mathrm{~kg}$ human being with a $1 \mathrm{~m}^{2} / \mathrm{kg}$ body weight inner lung surface, ${ }^{45}$ a lung minute volume of $13 \mathrm{~L} / \mathrm{min}$, $20 \%$ lung deposition of particles, ${ }^{46}$ and an 8-hour working day shift, it would need a mean aerosol concentration of about $4800 \mathrm{mg} / \mathrm{m}^{3}$ to result in this lung surface load during one working day. This concentration is more than 25 times higher than the highest aerosol concentration, which has been measured in the aerosol chamber during this study as a worst-case scenario and may therefore have no relevance for the working place situation.

The gas-phase component formaldehyde on the contrary was present in concentrations of up to $13 \mathrm{mg} / \mathrm{m}^{3}$. It has been shown ${ }^{17}$ that this in vitro inhalation model demonstrates acute toxicity of formaldehyde by a decrease of cellular viability at concentrations of $20 \mathrm{ppm}$ and higher. Hence, actual data are in good correlation with the historical data of the single-substance acute in vitro inhalation test of formaldehyde. Moreover, the in vivo (rat) $\mathrm{LC}_{50}$ inhalation acute toxicity value for formaldehyde is measured to be $>350^{47}$ and $<463 \mathrm{ppm}$ in Wistar rats ${ }^{48}$; local signs of toxicity indicated by respiratory epithelial injury such as erosion and hemorrhages of the nasal turbinates, internalized cilia occurring at $6-15 \mathrm{ppm},{ }^{48}$ and indications of toxicity in man (irritation in throat) starting at $1-2 \mathrm{ppm}^{49}$ Hence, it is also in agreement with in vivo data that formaldehyde at this concentration level does not induce cellular toxicity.

\section{Conclusion}

The study displays the present possibilities in acute local lung toxicity testing of aerosols in vitro and the potential to further evaluate biological effects from inhalable complex aerosols from consumer products, environment, or workplace atmospheres. Positive and negative controls with relevance for human inhalation were applied under a highly relevant testing regimen for the test aerosol and induced dose-dependent and significant effects. The test item was used in a relevant procedure, and an optimized experimental setup was developed to sample as much as possible constituents of the aerosol released from the product. By the concurrent testing of relevant controls and surface-based dosimetry, a basis is given for a toxicity ranking from in vitro to in vivo. In the first exemplary application with a hair straightening agent, the in vitro inhalation model characterized the responses toward the test item as less harmful with respect to acute toxicity and irritative potential in comparison to the positive controls, SDS and copper sulfate. Only small, nonsignificant effects of these aerosols were found in comparison to negative control situations with respect to IL-8 secretion in a certain experimental situation (five hair treatment). Since such effects were also found at high cellular surface loads with lactose as a negative control, it might be an advanced task in the future to evaluate if nonsubstance-specific effects such as the presence of high particle masses or particle surfaces may be responsible for incidents such as this in a cell-based in vitro inhalation model. Although it seems unlikely that the respective exposure concentrations are relevant for the acute real environmental human exposure situation during a working day due to a worst-case scenario, further studies might evaluate if these results have also an implication for the respective risk assessment.

In summary, the study renders the established testing scenario as a valuable tool to get insight into biological effects of inhalable material. No significant effects of the test item were found under this testing regimen. By the combination 
of relevant procedures from the fields of aerosol generation, cell exposure, cell culture, cellular readout technologies, and risk assessment, an efficient basis is defined for continuing application to other test materials and consumer products.

\section{Author Disclosure Statement}

R.F. and A.F. are both employees of a company selling cosmetic products, including the Kerasilk Keratin Treatment, which is reported in the publication. Until December 2016, C.G. was also an employee of this company selling cosmetic products. All other authors are employees of the Fraunhofer Gesellschaft, a patentee of the ExpoCube Technology (DE 102013109 450).

\section{References}

1. Kienzler A, Bopp SK, van der Linden S, et al. Regulatory assessment of chemical mixtures: requirements, current approaches and future perspectives. Regul Toxicol Pharmacol 2016:80;321-334.

2. Regulation (EC) No $1223 / 2009$ of the European Parliament and of the Council on Cosmetic Products, 2009, L342/59.

3. Knebel JW, Ritter D, Aufderheide M. Exposure of human lung cells to native diesel motor exhaust-development of an optimized in vitro test strategy. Toxicol In Vitro 2002: 16;185-192.

4. Lichtveld KM, Ebersviller SM, Sexton KG, et al. In vitro exposures in diesel exhaust atmospheres: resuspension of PM from filters verses direct deposition of PM from air. Environ Sci Technol 2012:46;9062-9070.

5. Ritter D, Knebel JW, Aufderheide M. Exposure of human lung cells to inhalable substances: a novel test strategy involving clean air exposure periods using whole diluted cigarette mainstream smoke. Inhal Toxicol 2003:15;67-84.

6. Ritter D, Knebel J, Aufderheide M. Comparative assessment of toxicities of mainstream smoke from commercial cigarettes. Inhal Toxicol 2004:16;691-700.

7. Thorne D, Larard S, Baxter A, et al. The comparative in vitro assessment of e-cigarette and cigarette smoke aerosols using the gH2AX assay and applied dose measurements. Toxicol Lett 2017:265;170-178.

8. Galezowska $\mathrm{G}$, Chraniuk M, LidiaWolska L. In vitro assays as a tool for determination of VOCs toxic effect on respiratory system: a critical review. Trends Anal Chem 2016:77; 14-22.

9. Liu FF, Peng C, Ng JC. BTEX in vitro exposure tool using human lung cells: trips and gains. Chemosphere 2015:128; 321-326.

10. Stalter D, Dutt M, Escher BI. Headspace-free setup of in vitro bioassays for the evaluation of volatile disinfection by-products. Chem Res Toxicol 2013:26;1605-1614.

11. Latvala S, Vare D, Karlsson HL, et al. In vitro genotoxicity of airborne Ni-NP in air-liquid interface. J Appl Toxicol 2017:37;1-8.

12. Secondo LE, Lie NJ, Lewinski NA. Methodological considerations when conducting in vitro, air-liquid interface exposures to engineered nanoparticle aerosols. Crit Rev Toxicol 2017:47;225-262.

13. Müller L, Comte P, Czerwinski J, et al. New exposure system to evaluate the toxicity of (scooter) exhaust emissions in lung cells in vitro. Environ Sci Technol 2010:44;2632-2638.

14. European Chemicals Agency ECHA. Search for chemicals; www.echa.eu (last accessed Mar. 2, 2018).
15. Peteffi GP, Venzon Antunes M, Carrer C, et al. Environmental and biological monitoring of occupational formaldehyde exposure resulting from the use of products for hair straightening. Environ Sci Pollut Res 2016:23;908.

16. Galli CL, Bettin F, Metra P, et al. Novel analytical method to measure formaldehyde release from heated hair straightening cosmetic products: impact on risk assessment. Regul Toxicol Pharmacol 2015:72;562-568.

17. Ritter D, Knebel J. Investigations of the biological effects of airborne and inhalable substances by cell-based in vitro methods: fundamental improvements to the ALI concept. Adv Toxicol 2014:Article ID 185201, http://dx.doi.org/ 10.1155/2014/185201 (last accessed Mar. 2, 2018).

18. ANSYS Fluent Theory Guide, release 16.0. Chapter 2: flows with moving reference frames. Canonsburg, USA: ANSYS, Inc.; 2015.

19. Broßel D, Tröller S, Dziurowitz N, et al. A thermal precipitator for the deposition of airborne nanoparticles onto living cells—rationale and development. J Aerosol Sci 2013: $63 ; 75-86$.

20. Brodbeck C, Knebel J, Ritter D, et al. Applying CFD for the design of an air-liquid interface in-vitro testing method for inhalable compounds. In: Scientific Computing and Algorithms in Industrial Simulations. M Griebel, A Schüller, MA Schweitzer (eds); pp. 229-243. Berlin, Germany: Springer; 2017.

21. WHO Copper EHC 200. Environmental Health Criteria. Geneva: World Health Organization; 1998, p. 382.

22. PubChem. Copper sulfate. Chapter 12 safety and hazards. In PubChem Open Chemistry Database. 2017. https://pubchem .ncbi.nlm.nih.gov/compound/Copper_sulfate\#section=Safetyand-Hazards (last accessed 14 Nov 2017).

23. NIOSH Copper Sulfate, International Chemical Safety Cards (ICSC: 0751). The National Institute for Occupational Safety and Health. 2014. www.cdc.gov/niosh/ipcsneng/ neng0751.html (last accessed Nov. 14, 2017).

24. Engelking LR. Chapter 50: copper. In: Textbook of Veterinary Physiological Chemistry $3^{\text {rd }}$ ed. pp. 314-318. London, UK: Academic Press; 2015.

25. Ellingsen DG, Horn N, Aaseth J. Chapter 26-copper. In: Handbook on the Toxicology of Metals $3^{\text {rd }}$ ed. GF Nordberg et al. (eds); pp. 529-546. London, UK: Academic Press; 2007.

26. USDA. Copper sulfate, technical evaluation report. United States Department of Agriculture, Agricultural Marketing Service, Agricultural Analytics Division for the USDA National Organic Program. 2015; 18 p. www.ams.usda.gov/ sites/default/files/media/Copper\%20Sulfate\%203\%20TR\% 202015.pdf (last accessed Nov. 14, 2017).

27. Thompson T, Freestone D, Michalczyk AA. Copper sulphate. UK Poison Information Documents (UK PID Monograph). 1998 www.inchem.org/documents/ukpids/ukpids/ ukpid56.htm (last accessed Nov. 14, 2017).

28. Mathew P, Austin RD, Varghese SS, et al. Effect of copperbased fungicide (bordeaux mixture) spray on the total copper content of areca nut: implications in increasing prevalence of oral submucous fibrosis. J Int Soc Prev Community Dent 2015:5;283-289.

29. Thompson T, Freestone D, Michalczyk AA, et al. Copper levels in buccal cells of vineyard workers engaged in various activities. Ann Occup Hyg 2012:56;305-314.

30. Pimentel JC, Marques F. "Vineyard sprayer's lung": a new occupational disease. Thorax 1969:24;678-688.

31. Bondi CA, Marks JL, Wroblewski LB, et al. Human and environmental toxicity of sodium lauryl sulfate (SLS): evidence 
for safe use in household cleaning products. Environ Health Insights 2015:9;27-32.

32. Regulation (EC) No 1907/2006 of the European Parliament and of the Council concerning the Registration, Evaluation, Authorisation and Restriction of Chemicals (REACH), establishing a European Chemicals Agency, amending Directive 1999/45/EC and repealing Council Regulation (EEC) No 793/93 and Commission Regulation (EC) No 1488/94 as well as Council Directive 76/769/EEC and Commission Directives 91/155/EEC, 93/67/EEC, 93/105/EC and 2000/21/EC, 2006, L396/1.

33. Regulation (EC) No 528/2012 of the European Parliament and of the Council concerning the making available on the market and use of biocidal products, 2012, L167/1.

34. Lieber M, Smith B, Szakal A, et al. A continuous tumor cellline from a human lung carcinoma with properties of type-II alveolar epithelial cells. Int. J Cancer 1976:17;62-70.

35. Nardone LL, Andrews SB. Cell line A549 as a model of the type II pneumocyte. Biochim Biophys Acta 1979:573; 276-295.

36. Mosmann T. Rapid colorimetric assay for cellular growth and survival: application to proliferation and cytotoxicity assays. J Immunol Methods 1983:65;55-63.

37. Slater TF, Sawyer B, Sträuli U. Studies on succinatetetrazolium reductase systems: III. Points of coupling four different tetrazolium salts. Biochim Biophys Acta 1963: 77;383-393.

38. Coquette A, Berna N, Vandenbosch A, et al. Analysis of interleukin- $1 \alpha$ (IL-1 $\alpha$ ) and interleukin-8 (IL-8) expression and release in in vitro reconstructed human epidermis for the prediction of in vivo skin irritation and/or sensitization. Toxicol In Vitro 2003:17;311-321.

39. Van der Veen JW, Paskel RF, Smits NA, et al. The involvement of the Toll-like receptor signaling and Nrf2-Keap1 pathways in the in vitro regulation of IL- 8 and HMOX1 for skin sensitization. J Immunotoxicol 2016:13;1-6.

40. Jeong J, Choi J. Use of adverse outcome pathways (AOP) in chemical management: potential advantages and limitations. Environ Health Toxicol 2017. [Epub ahead of print]; DOI: 10.5620/eht.e2018002.
41. Scientific Committee on Occupational Exposure Limits (SCOAL). Recommendation 125 formaldehyde. 2015. https:// circabc.europa.eu/sd/a/d44aedf4-8e61-47b4-96c6-91a6ff3139f 7/2015-11-16v11\%20REC-125\%20Formaldehyde\%20stage \%2040.20.pdf (last accessed Jan. 23, 2018).

42. Baldrick P, Bamford DG. A toxicological review of lactose to support clinical administration by inhalation. Food Chem Toxicol 1997:35;719-733.

43. Schierliess R. The MTT assay as tool to evaluate and compare excipient toxicity in vitro on respiratory epithelial cells. Int J Pharm 2011:411;98-105.

44. De Jesus Valle MJ, Dinis-Oliveira RJ, Carvalho F, et al. Toxicological evaluation of lactose and chitosan delivered by inhalation. J Biomater Sci Polym Ed 2008:19;387-397.

45. Dunnill MS. Postnatal growth of the lung. Thorax 1962:17; 329.

46. Rothe H, Fautz R, Gerber E, et al. Special aspects of cosmetic spray safety evaluations: principles on inhalation risk assessment. Toxicol Lett 2011:5;97-104.

47. Nagorny PA, Sudakova ZA, Schablenko SM. On the general toxic and allergic action of formaldehyde. Gig Tr Prof Zabol 1979:1;27-30.

48. ECHA registration dossier for formaldehyde. https://echa .europa.eu/de/registration-dossier/-/registered-dossier/15858/ 7/3/3/?documentUUID=ce61ff55-e87d-4080-88e3-fb90c 8055391 (last accessed Mar. 2, 2018).

49. Andersen I, Molhave L. Controlled human studies with formaldehyde. In: Formaldehyde Toxicity. JE Gibson (ed); pp. 155-165. Washington, DC: Hemisphere Publishing; 1983.

Address correspondence to:

Dr. Detlef Ritter

Fraunhofer Institute for Toxicology and Experimental Medicine Nikolai-Fuchs-Str. 1 D-30625 Hannover Germany

E-mail:detlef.ritter@item.fraunhofer.de 